\title{
Full term newborns in non-nutritive suction evaluationand their relation on feeding performance
}

Yasmin Vieira Teixeira Alves 1

(iD https://orcid.org/0000-0003-2712-3353

Jéssica Caroline de Jesus Santos 2

iD https://orcid.org/0000-0001-6683-0478

Ikaro Daniel de Carvalho Barreto 3

https://orcid.org/0000-0001-7253-806X
Cristina Ide Fujinaga 4

(iD) https://orcid.org/0000-0003-0852-1567

Andréa Monteiro Correia Medeiros 5

iD https://orcid.org/0000-0002-4930-7623

1,2,5 Departamento de Fonoaudiologia. Universidade Federal de Sergipe. Cidade Univ. Prof. José Aloísio de Campos. Av. Marechal Rondon, s/n, Jd. Rosa Elze. São Cristovão, SE, Brasil. CEP 49100-000. E-mail: andreamcmedeiros@gmail.com

3 Universidade Federal Rural de Pernambuco. Recife, PE, Brasil

4 Departamento de Fonoaudiologia. Universidade Estadual do Centro-Oeste. Irati, PR, Brasil.

\section{Abstract}

Objectives: To investigate full term newborns suction pattern in non-nutritive suction and their feeding performance.

Methods: An analytical descriptive study was carried out from November 2016 to March 2017, with 50 dyads mothers/newborns through the non-nutritive suction evaluation and a direct observation on the newborn's performance on feeding. The data were distributed through simple and relative frequencies (percentages) when categorical or by mean, maximum, minimum and the standard deviation when is continuous, discrete or ordinal. To evaluate the mean differences, the Student's t test was used with significance level of 5\%.

Results: There were significant differences among the newborn's mandible movement ("newborn's mouth slightly open" $p=0,005)$, suction ("cheek strain during feeding" $p<0,001)$ and dyad mother and newborn positioning ("breasts supported with fingers on the areola" $p=0,041$ and baby's neck or trunk turned" $p=0,041$ ).

Conclusions: Newborns that presented changes in their mandible movement on the NonNutritive Suction (NNS) also presented difficulties in feeding. The newborn's knowledge on suction pattern through the NNS has proven to be an important strategy that may help identify possible difficulties during feeding.

Key words Maternal and child health, Maternal Breastfeeding; Stomatognathic system, Suction; Mandible 


\section{Introduction}

A healthy newborn (NB) has all the necessary conditions for suctioning to be anatomically prepared and equipped with oral reflexes that favor this performance. ${ }^{1}$ To suck enables the possibility to supply the newborn's nutritional needs, improve their mobility, posture and tone of the orofacial muscles involved, ${ }^{2}$ promoting oral motor control maturation, intra and extraoral muscle balance, tooth eruption and establish nasal breathing. ${ }^{3-5}$

The suction is characterized by four mandibular movements: opening, protruding, closing and retrusion. Through this mandibular movement, especially those performed in the vertical plane, the newborn presses the breast milk ducts to extract breastmilk. 6 This mechanism should be in perfect synchronization and coordination with the newborn's swallowing and breathing, to prevent any kind of choking and/or bronchoaspiration.7-10

The literature indicates breastmilk as the ideal source of nutrients, $2,5,11-13$ and that the duration of breastfeeding has been linked to early onset of their stimulation. $3,14,15$ Thus, there is a necessity to verify the possible early difficulties in the feeding process. ${ }^{3}$

Regarding the newborn's oral skills, the speech therapist is one of the qualified professionals to work along with the dyads in the first hours of the newborn's life.4,16 It is his/her responsibility to evaluate and assist the feeding process in this population. 3,13,17 Although the non-nutritive suction technique (NNS) has traditionally been used to evaluate the newborns' feeding pattern,16-19 it is not yet proven to be effective to predict the newborn's behavior during feeding. 20

In order to the suction occur adequately, the newborn should have good motor stability and mobility, 18 adequate development of the stomatognathic system and a favorable state of consciousness (preferably alert), as well as healthy anatomical-clinical conditions. $1,3,15,20-22$

Therefore, this study aimed to investigate full term newborns' suction pattern in the NNS and their feeding performance.

\section{Methods}

This present research was approved by the Research Ethics Committee at the Universidade Federal de Sergipe under the document number: 53611316.0.0000.5546 / 2016. All the participants previously signed the Informed Consent Form.

This is a descriptive analytical study that compared the performance of mother-newborn dyads in feeding by applying the "Protocolo de Avaliação da Mamada - UNICEF",23 (Assessment Protocol on Feeding) measurement in which details the aspects of the mother and the newborn on feeding, with variables contemplated in the "Instrumento de avaliação da sucção do recém-nascido na alimentação no seio materno",20 (Instrument to assess newborn's suction in breastfeeding) which addresses: tongue posture at ease, cannulation and tongue and mandible movement during the NNS.

The Protocolo de Avaliação da Mamada UNICEF23 (Assessment Protocol on Feeding) consists of signs that the suckling is going well and signs of possible difficulties. It is possible to point out more than one alternative. The observed signs are as followed:

Mother: seems to be healthy; relaxed and comfortable; signs of bonding between mother and baby; or, seems to be unwell or depressed; tense or uncomfortable; no eye contact with the baby. 23

Baby: looks healthy; calm and relaxed; looks for the breast if he/she is hungry; or sleepy or sick; impatient or crying; does not look for the breast.23

Breast: looks healthy; no pain or discomfort; supported by the fingers away from the nipple; or, red, swollen or cracked; sore breast or nipple; breast supported by the fingers on the areola.

Baby's position: baby's head and trunk aligned; baby's body very close to the mother's body; baby's buttocks supported; baby's nose at nipple level; or, baby with neck or trunk turned; baby is distant of mother; baby is only supported by the head or back; Baby's nose is above or below the nipple. 23

Baby's breast grip: areola is noticeable above the baby's mouth; baby's mouth is wide open; lower lip facing outwards; baby's chin touching the breast; or, areola is noticeable below the baby's mouth; baby's mouth is barely open; lips forward or inward; baby's chin does not touch the breast. 23

Suction: Slow and deep suctions interspersed with pauses; round cheek during feeding; baby loosens the breast when he/she end the feeding; mother presents oxytocin reflex signs; or, quick suctions; cheek strain during feeding; mother removes the baby from her breast; mother without oxytocin reflex signs. 23

The NNS assessment instrument consists of 4 items, whose score ranges from 0 to 2 points. Thus, the newborn can obtain from 0 to 8 points, totaling a maximum score of 8 points, 20 as explained below:

\section{Oral Posture20}

Tongue Posture: Flat (2); Elevated, Retracted or Protracted (0). 


\section{Non-nutritive Suction20}

Tongue movement: Adequate (2); Altered (1); Absent (0).

Tongue Cannulation: Present: (2); Absent (0).

Mandible movement: Adequate (2); Altered (1); Absent (0).

In order to reach the maximum score during this procedure, the baby should present: 20

- Tongue posture resting: Tongue should be resting on the oral cavity floor with a rounded tip;

- Presence of tongue cannulation: elevation of the tongue on lateral edges, forming a central groove;

- Tongue movement: anteroposterior and coordinated wave movements of the tongue;

- Mandible movement: smooth, rhythmic articulated movements of the opening, protruding, closing and retrusion during the suction.

The data collection phase was carried out over a period of four months (from November 2016 to March 2017) of visits done by researchers to the Alojamento Conjunto (ALCON) (Maternity Accommodation) three times a week. During this period, 84 mother-newborn dyads were assisted and randomly drawn to be included for the total number of hospitalized dyads, counted in the daily unit census, organized in a single list. However, of the 84 mothers followed, only 50 mother-newborn dyads met the inclusion and exclusion criteria, which composed the present study.

The inclusion criteria were: healthy newborns with an Apgar score equal to or greater than 7 in the first minute of life, born at term, both sexes, have been fed at least two hours before the procedure, whose mothers were apt either organic and emotional aspects to feeding and wished to breastfeed their children.

The exclusion criteria were: newborns with craniofacial anomalies, syndromes, heart disease or respiratory disorders that made suckling difficult, were fed less than two hours at the time of the procedures. Mothers were also excluded if presented organic and psychological impediments, who had medical advice and/or health team contraindicate breastfeeding.

A minimum puerperium period was respected before performing the procedures, so that all puerperal women could supposedly be in similar clinical recovery conditions: 24 hours for women who had normal delivery and 48 hours for those who underwent surgical childbirth.

After explaining the procedures and signing the informed consent form, a questionnaire was applied for the mothers to characterize the mother-newborn dyads.

The research was carried out in two stages, namely:

\section{Stage I}

The application of the "Instrumento de avaliação da sucção em recém-nascido a termo com vistas à alimentação ao seio materno"20 (Assessment instrument on full term newborns' suction on breastfeeding consultations). Initially, the researcher registered the tongue posture at rest. This registration was made by observing without manipulation or, when necessary, by gently lowering the newborn's mandible, allowing intraoral inspection. Immediately afterwards, a gloved little finger, with the palm facing downwards, was introduced into the newborn's oral cavity for the NNS evaluation, and with the other hand supporting the newborn's back. The test would last 1 minute, a digital stopwatch was used to time.

\section{Stage II}

Immediately after the end of the first stage, feeding was observed on the maternal breast without any interference from the researchers, and the data were registered in the "Protocolo de Avaliação da Mamada -UNICEF".23 "Assessment Protocol on Feeding). This instrument was used as a reference because it is considered as the "gold standard", 20 regarding to feeding evaluation, allowing to elucidate the signs that suckling is going well or possible difficulties. It is noteworthy that feeding was evaluated from the beginning to the end.

After concluding the application of the instruments and ending all the research procedures, guidance was provided and assist was given to the dyads, focusing on the difficulties they had seen during the evaluation.

The collected data were described by simple and relative frequencies (percentages) when categorical or mean, maximum, minimum and standard deviation when continuous, discrete or ordinal. To assess the mean differences, the Student's t-test was used with a significance level of $5 \%$. The software used was R Core Team 2017.

\section{Results}

The mothers' age range varied from 14 to 38 years (mean age $=24.7 ; \mathrm{SD}=6.30), 30(60 \%)$ puerperal women were primiparous. Most of the professions mentioned were stay-at-home housewife $(n=38$; $76 \%)$ and student $(\mathrm{n}=5 ; 10 \%)$.

In relation to schooling, $28(56 \%)$ mothers 


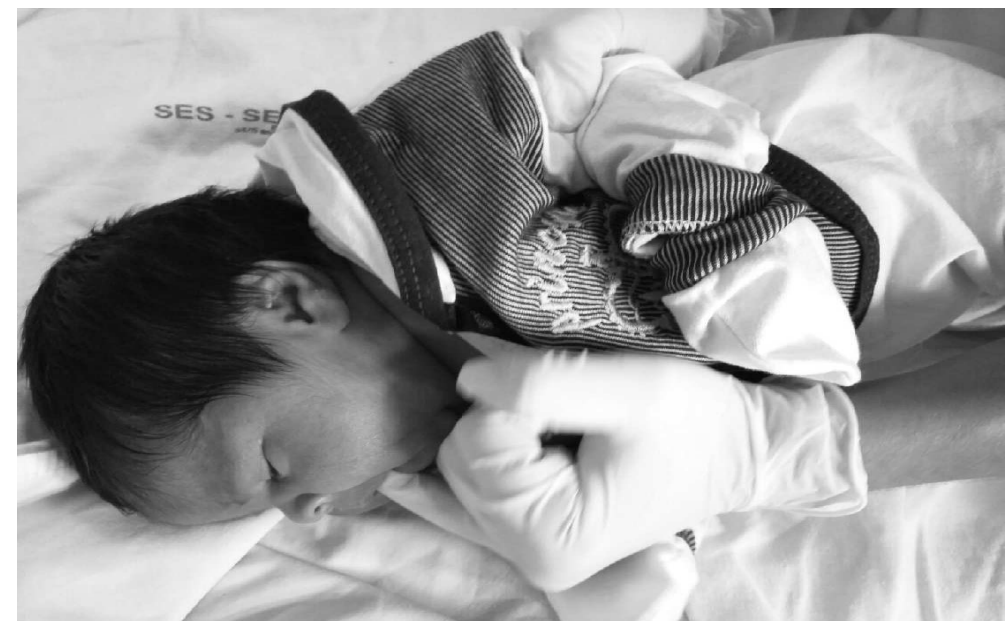

Source: Researchers Collection.

reported $\geq 8$ years of schooling while $22(44 \%)$ referred to less than 8 years.

Regarding to newborns, 33 (66\%) were male and $17(34 \%)$ female with an average gestational age of $39.6(\mathrm{SD}=1.35)$ weeks.

The results regarding to the NNS evaluation are shown in Table 1, with scores ranging from 0 to 2 points for each item. The newborns could have from 0 to 8 points as a total score (sum of all evaluated items).

Resting tongue posture and adequate tongue movement were observed in all newborns in this study. In the NNS evaluation, alterations were identified only in the tongue cannulation and the newborn's mandible movement, according to Table 1.

As for the performance assessmenton the dyad's feeding, all mothers appeared to be healthy and relaxed at the time of the assessment, and all the dyads had at least one difficulty during feeding observation, as shown in Table 2.

When comparing newborn's suction pattern during the NNS assessment with feeding performance, no significant differences were observed in any of the following aspects: newborn's resting tongue posture, tongue movement and tongue cannulation.

When comparing the mandible movement during the NNS evaluation with feeding performance, significant differences were evidenced for "breasts supported by fingers around the areola" $(p=0.041)$; "Baby's neck or trunk turned" ( $p=0.041)$; "Baby's mouth a little opened" $(p=0.005)$; "Cheek strain during feeding" ( $p<0.001)$, as observed in Table 3 .

\section{Discussion}

Regarding to posture and tongue movement in this research, which considered full term newborns, all the participants were adequate at the time of the NNS evaluation and no significant differences were found when related to feeding performance. This finding is in line with the literature which states that the coordinated suction is fully established by the $37^{\text {th }}$ gestational week. $4,13,17$

In relation to tongue cannulation, although this study did not show significant differences regarding this variable, its importance for good suction is highlighted,24,25 as this dynamic function, at a proper positioning, especially the newborn's head posture, is directly related to the effective grip, which facilitates tongue movement in the oral cavity. 18,24

It is noteworthy that tongue cannulation is a difficult variable to measure, but its observation is part of the clinical routine to evaluate newborn's suction performance. ${ }^{26}$ The conformation of the tongue during suction contributes to the formation of the oral cavity seal on the maternal breast17,27 making feeding safer and more efficient. 26

As for the "mandible movement" variable, the 
Table 1

Characteristic of full term newborns' oral tongue posture and suction pattern. Aracaju, 2017.

\begin{tabular}{lccc}
\hline & & $\mathrm{N}=\mathbf{5 0}$ (100\%) \\
\cline { 2 - 4 } Variables & $\mathrm{N}$ & $\%$ & Total Score \\
\hline Oral tongue posture & & & \\
$\quad$ Protruded (0) & 0 & 0.00 & 2 \\
$\quad$ Elevated (0) & 0 & 0.00 & 2 \\
$\quad$ Retracted (0) & 0 & 0.00 & 2 \\
$\quad$ Flat (2) & 50 & 100.00 & 2 \\
Tongue movememt & & & 2 \\
$\quad$ Absent (0) & 0 & 0.00 & 2 \\
$\quad$ Altered (1) & 0 & 0.00 & 2 \\
$\quad$ Adequate (2) & 50 & 100.00 & 2 \\
Tongue Cannulation & & & 2 \\
$\quad$ Absent (0) & 1 & 2.00 & 2 \\
$\quad$ Present (2) & 49 & 98.00 & 2 \\
Mandible Movement & & & 2 \\
$\quad$ Absent (0) & 0 & 0.00 & 2.00 \\
$\quad$ Altered (1) & 4 & 92.00 & 2 \\
$\quad$ Adequate (2) & 46 & & 2 \\
\hline
\end{tabular}

Oral tongue posture - Protruded $=$ tongue over the lips, Elevated $=$ tip of tongue pressing palate, Retracted $=$ tongue retracting to the back of oral cavity, Flat $=$ Tongue accommodated on the floor of oral cavity with rounded tip. Tongue Movement - Absent $=$ absence of tongue movement, Altered = posteroanterior and uncoordinated tongue movement during stimulus, Adequate $=$ Antero-posterior and coordinated tongue movement during stimulus. Cannulation Absent $=$ no elevation of the lateral edges of the tongue and formation of central groove in the presence of stimulus, Present $=$ with elevation of the lateral edges of the tongue forming a central groove in the presence of stimulus. Mandible Movement - Absence $=$ no movement, Altered $=$ Exacerbated or restricted opening, locking or irregular movements, Adequate $=$ Wide opening with smooth, rhythmic opening, protruding, closing and retracting movements. These variables apprehend a score ranging from 0 to 2, totaling a maximum score of 8 points. 
Table 2

Dyadsperformance (mothers/newborns) during feeding. Aracaju, 2017.

\begin{tabular}{|c|c|c|}
\hline Variables & $\mathbf{N}$ & $\%$ \\
\hline Mother seems to be unwell or depressed & 0 & 0.00 \\
\hline Mother looks tense or uncomfortable & 4 & 8.00 \\
\hline No eye contact with baby & 2 & 4.00 \\
\hline Baby looks sleepy or sick & 1 & 2.00 \\
\hline Baby is impatient or crying & 9 & 18.00 \\
\hline Baby does not look for the breast & 1 & 2.00 \\
\hline Red, swollen or sore breast & 8 & 16.00 \\
\hline Sore breast or nipple & 18 & 36.00 \\
\hline Breast supported by fingers on areola & 15 & 30.00 \\
\hline Baby's neck or trunk turned & 15 & 30.00 \\
\hline Baby is distant of the mother & 9 & 18.00 \\
\hline Baby is supported only by the head or back & 7 & 14.00 \\
\hline Baby's nose above or below the nipple & 2 & 4.00 \\
\hline Areola is more visible below baby's mouth & 11 & 22.00 \\
\hline Baby's mouth a little opened & 18 & 36.00 \\
\hline Lips are outward or inward & 16 & 32.00 \\
\hline Baby's chin does not touch the breast & 6 & 12.00 \\
\hline Quick suctions & 8 & 16.00 \\
\hline Cheek strain during feeding & 5 & 10.00 \\
\hline Mother removes baby from her breast & 16 & 32.00 \\
\hline Mother without oxytocin reflex signs & 20 & 40.00 \\
\hline
\end{tabular}

$\mathrm{N}=$ number of dyads (mothers/newborns). 
Table 3

Comparison between newborn's mandible movement in the non-nutritive suction and feeding performance. Aracaju, 2017.

\begin{tabular}{|c|c|c|c|}
\hline \multirow{2}{*}{ Variables } & \multicolumn{2}{|c|}{ Mean \pm SD } & \multirow{2}{*}{$p$} \\
\hline & No & Yes & \\
\hline Mother seems to be unwell or depressed & - & - & - \\
\hline Mother looks tense or uncomfortable & $1.93 \pm 0.25$ & $1.75 \pm 0.50$ & 0.199 \\
\hline No eye contact with the baby & $1.92 \pm 0.28$ & $2.00 \pm 0.00$ & 0.678 \\
\hline Baby looks sleepy or sick & $1.92 \pm 0.28$ & $2.00 \pm 0.00$ & 0.771 \\
\hline Baby is impatient or crying & $1.90 \pm 0.30$ & $2.00 \pm 0.00$ & 0.339 \\
\hline Baby does not look for the breast & $1.92 \pm 0.28$ & $2.00 \pm 0.00$ & 0.771 \\
\hline Red, swollen or sore breast & $1.93 \pm 0.26$ & $1.88 \pm 0.35$ & 0.617 \\
\hline Sore breast or nipple & $1.91 \pm 0.30$ & $1.94 \pm 0.24$ & 0.641 \\
\hline Breast supported by fingers on areola* & $1.97 \pm 0.17$ & $1.80 \pm 0.41$ & 0.041 \\
\hline Baby's neck or trunk turned* & $1.97 \pm 0.17$ & $1.80 \pm 0.41$ & 0.041 \\
\hline Baby is distant of mother & $1.93 \pm 0.26$ & $1.89 \pm 0.33$ & 0.711 \\
\hline Baby is supported only by the head or back & $1.93 \pm 0.26$ & $1.86 \pm 0.38$ & 0.518 \\
\hline Baby's nose above or below the nipple & $1.92 \pm 0.28$ & $2.00 \pm 0.00$ & 0.678 \\
\hline Areola is more visible below the baby's mouth & $1.95 \pm 0.22$ & $1.82 \pm 0.40$ & 0.165 \\
\hline Baby's mouth is a little opened* & $2.00 \pm 0.00$ & $1.78 \pm 0.43$ & 0.005 \\
\hline Lips are outward or inward & $1.97 \pm 0.17$ & $1.81 \pm 0.40$ & 0.056 \\
\hline Baby's chin does not touch the breast & $1.93 \pm 0.25$ & $1.83 \pm 0.41$ & 0.415 \\
\hline Quick suctions & $1.90 \pm 0.30$ & $2.00 \pm 0.00$ & 0.373 \\
\hline Cheek strain while feeding * & $1.98 \pm 0.15$ & $1.40 \pm 0.55$ & $<0.001$ \\
\hline Mother removes baby from her breast & $1.94 \pm 0.24$ & $1.88 \pm 0.34$ & 0.431 \\
\hline Mother without oxytocin reflex signs & $1.90 \pm 0.31$ & $1.95 \pm 0.22$ & 0.533 \\
\hline
\end{tabular}

*Comparisons with $p<0.05, S D=$ standard deviation. Student's $t$ test. 
differences were observed regarding items related to the grip, suction and positioning. It is known that all these aspects need to be adequate and synchronized in order for the breast suction to perform well. $3,15,18,26$

The mandible offers a stable base for tongue movements, assisting in the creation of intraoral pressure and with its vertical and horizontal movements compresses the areola resulting in the release of milk. ${ }^{28}$ In its function, by acting in conjunction with the tongue, is synchronized until about the infant's six months of life.6,27

In regards to the grip, when the newborn catches the nipple, the suction reflex is triggered, with the tongue and mandible movement. In this study, newborns with "mouth a little opened" were identified. A proper grip gives support for the correct movement of the oral structures during feeding, 3 although this influences the newborn's body to organize. $14,24,27$

Regarding to the newborn's positioning, the present study observed "baby with neck or trunk turned". For the feeding to be effective, which includes proper mandible movement during suction, it is necessary that the newborn is closer and faces the mother, with supported buttocks, facilitating the grip and, consequently, the suction.3,13,17,29

Still in regards to positioning, changes were also observed on the mother's posture, in which "breast supported with the finger on the areola" was observed. Therefore, it is emphasized that puerperal women's hand posture wrapped around the breast should also be taken into consideration because the pressure of the fingers on the areola can clog the milk ducts, causing milk retention on the location 13,23,24 This may influence the action of the orofacial muscles involved, requiring a greater effort of the infant during the suction, 28 which was also observed during the feeding evaluation.

In aspects related to suction, there was a significant difference for "cheek strain" during the feeding evaluation. The mandible, through its movements of: lowering, protrusion, closure and retraction play an important role in the formation of the intraoral pressure, which concomitantly with the tongue and palate occlusion on the nipple to help in the extraction of breastmilk, ${ }^{6}$ providing smoother contraction of the newborn's cheek muscles during feeding. ${ }^{17}$

Moreover, the alterations in the mandible movement during the suction may also be the result of the newborn's owncraniofacial characteristics. The neonate is a pseudo-retrognathus, that is, has a small and retracted mandible, and its oral cavity is completely filled with the tongue. 30 In these condi- tions, at first, the newborn does not yet have the mandible stability necessary for efficient movement of the mouth for suction, but has fat pads, called "sucking pads" that help in this task. ${ }^{30}$

Breast and nipple conditions could also interfere with the newborn's suction, grasping, and tongue movement pattern, as the engorged breast can make the breast dense and flatten the nipple, hindering nipple snapping and milk flow through the milk ducts, 15 and nipple injuries are due to improper grip and poor positioning of the dyad tending to impair the nurse's sense of well-being and is considered one of the main reasons for early weaning; 15,29 however, in this present study, these aspects were not significant, probably because feeding was observed in the first hours of life, when there is still a low incidence of engorged breasts.

Regarding the nipple anatomy, the literature 3,24 points out its conformation, especially flat and everted nipples can interfere with feeding and cause potential difficulties of the newborn to perceive the nipple and trigger the suction reflex, although this factor is not decisive for the performance and maintenance of breastfeeding, because the areola can serve as a nipple, and the mammary glands, when massaged during the suction, stimulates the production and ejection of milk.3,15,24 This aspect could not be elucidated from the feeding observation protocol used in this present study, which, although is considered the gold standard, does not include aspects regarding breast and nipple types.

Concerning the results obtained in this present study, attention is drawn to the problems related to the mother-newborn dyads posture and the poor quality of feeding that are interrelated with the difficulties of mandible movement. Thus, it is considered that adjusting the suction pattern and preparing mothers for the proper management of breastfeeding is of fundamental importance in the area of maternal and child health, especially inserted in the first care during the puerperal period.

Considering the difficulties of mandible movement, the non-nutritive suction technique (SNN), as pointed out in the literature, could continue to be used to reduce instability in the function, providing greater accuracy of tongue and mandible movements and greater future coordination among suction, swallowing and breathing 13,19,24 in addition to helping the speech therapist to identify possible suction difficulties that could influence the newborn's feeding performance. 20

It is worth mentioning that the literature presents several protocols for the evaluation of the breastfeeding process, $18,20,22$ and also for the evaluation of 
the NNS. 20

As a limitation of the study, the study design itself, having the recommended protocol and used as the gold standard, it does not refer to the observation of the breasts and nipples types, which these variables were not allowed to be analyzed when related to the newborn's performance in the NNS and also a small number of participants. For future studies, it is suggested that there should be an increase in the sample of mother-newborn dyads. Further studies may also be performed considering different populations, such as premature, low birth weight and syndromic newborns.

Despite this limitation, the results showed mandibular movements characteristics in NNS related to feeding pattern difficulties. These findings point to the necessity of speech therapy in this population, with appropriate actions for clinical management on maternal breastfeeding. The present study highlights the relevance of knowledge on the

\section{References}

1. Calegari FL, Barbieratto BJ, Fujinaga CI, Fonseca LMM, Oliveira CR, Leite AM. Prontidão do recém-nascido a termo durante a primeira mamada em alojamento conjunto. Rev Rene. 2016; 17 (4): 444-50.

2. Lopes TS, Moura Lde F, Lima MC. Breastfeeding and sucking habits in children enrolled in a mother-child health program. BMC Res Notes. 2014, 7 (362): 1-8.

3. Medeiros AMC, Santos JCJ, Santos DAR, Barreto IDC, Alves YVT. Speech-language therapy follow-up of breastfeeding in newborns in the first hours of life. Audiol Commun Res. 2017; 22: e1856.

4. Medeiros Andréa Monteiro Correia, Sá Thalyta Prata Leite de, Alvelos Conceição Lima, Novais Deborah Sabina Farias. Intervenção fonoaudiológica na transição alimentar de sonda para peito em recém-nascidos do Método Canguru. Audiol Commun Res. 2014; 19 (1): 95-103.

5. Miotto MHMB, Caxias FP, Campos DMKS, Ferreira LFPE, Barcellos LA. Aleitamento materno como fator de proteção contra a instalação de hábitos bucais deletérios. Rev CEFAC. 2014; 16 (1): 244-51.

6. Elad D, Kozlovsky P, Blum O, Laine AF, Po MJ, Botzer E, Dollberg S, Zelicovich M, Sira LB. Biomechanics of milk extraction during breast-feeding. Proc Natl Acad Sci USA. 2014; 111 (14): 5230-5.

7. Tamilia E, Taffoni F, Formica D, Ricci L, Schena E, Keller F, Guglielmelli E. Technological Solutions and Main Indices for the Assessment of Newborns' Nutritive Sucking: A Review. Sensors (Basel). 2014; 14 (1): 634-58.

8. Silva WF, Guedes ZCF. Tempo de aleitamento materno exclusivo em recém-nascidos prematuros e a termo. Rev CEFAC. 2013; 15 (1): 160-71.

9. Silveira LM, Prade LS, Ruedell AM, Haeffner LSBH, Weinmann ARM. Aleitamento materno e sua influência nas newborn's suction pattern, through the evaluation of the NNS by the speech therapist, as a strategy that can predict eventual signs of difficulties during breastfeeding.

\section{Authors' Contributions}

Medeiros AMC was responsible for the conception and design of the study, data analysis and interpretation, article review and final approval of the version to be published; Alves YVT and Santos JCJ were responsible for the conception and design of the study; data collection, analysis and interpretation and article writing; Barreto IDC was responsible for the statistical, analysis, interpretation of data and translation of the manuscript; Fujinaga CI was responsible for the conception and the design of the study, training for the collection, analysis and interpretation, and the review of manuscript. All authors approved the final version of the manuscript. habilidades orais de crianças. Rev Saúde Pública. 2013; 47 (1): 37-43.

10. Chen X, Bin X, Lihong G. Effects of breast-feeding duration, bottle-feeding duration and non-nutritive sucking habits on the occlusal characteristics of primary dentition. BMC Pediatr. 2015; 15 (46): 1-9.

11. Gertosio C, Meazza C, Pagani S, Bozzola M. Breastfeeding: gamut of benefits. Minerva Pediatr. 2016; 68 (3): 201-12.

12. Moimaz SAS, Rocha NB, Garbin AJI, Saliba O. A influência da prática do aleitamento materno na aquisição de hábitos de sucção não nutritivos e prevenção de oclusopatias. Rev Odontol UNESP. 2013; 42 (1): 31-6.

13. Brasil. Ministério da Saúde. Secretaria de Atenção à Saúde. Departamento de Ações Programáticas Estratégicas. Atenção humanizada ao recém-nascido de baixo peso: Método Canguru. Manual técnico. Brasília, DF; 2017.

14. Esteves TMB, Daumas RP, Oliveira MIC, Andrade CAF, Leite IC. Fatores associados à amamentação na primeira hora de vida: revisão sistemática. Rev Saúde Pública. 2014; 48 (4): 697-703.

15. World Health Organization. Infant and young child feeding: model chapter for text books for medical students and allied health professionals. Geneva: World Health Organization; 2009.

16. Santana MCCP, Moroni BCS, Alpino LL, Porto VFA. Atuação fonoaudiológica hospitalar junto a um processo de relactação e adoção: relato de caso. Rev CEFAC. 2014; 16 (6): 2048-52.

17. Calado DFB, Souza R. Intervenção fonoaudiológica em recém-nascido pré-termo: estimulação oromotora e sucção não-nutritiva. Rev CEFAC. 2012; 14 (1): 176-81. 
18. Fujinaga CI, Scochi CGS, Santos CB, Zamberlan NE, Leite AM. Validação do conteúdo de um instrumento para avaliação da prontidão do prematuro para início da alimentação oral. Rev Bras Saúde Mater Infant. 2008; 8 (4): 391-9.

19. Moreira Cláudia MD, Cavalcante-Silva Regina PGV, Miyaki Mitsuru, Fujinaga Cristina Ide. Efeitos da estimulação da sucção não nutritiva com dedo enluvado na transição alimentar em recém-nascido prematuro de muito baixo peso. Rev CEFAC. 2014; 16 (4): 1187-93.

20. Mosele PG, Santos JF, Godói VC, Costa FM, Toni PM, Fujinaga CI. Instrumento de avaliação da sucção do recémnascido com vistas à alimentação ao seio materno. Rev CEFAC. 2014; 16 (5): 1548-57.

21. Medeiros AMC, Leite STP, Alvelos CL, Raposo OFF. Effects of gustatory stimulation on the behavioral states of premature newborns. Audiol Commun Res. 2013; 18 (1): 50-6.

22. Sartorio BT, Coca KP, Marcacine KO, Abuchaim ESV, Abrão ACFV. Breastfeeding assessment instruments and their use in clinical practice. Rev Gaúcha Enferm. 2017; 38 (1): e64675.

23. Vieira AC, Costa AR, Gomes PG. Boas práticas em aleitamento materno: aplicação do formulário de observação e avaliação da mamada. Rev Soc Bras Enferm Ped. 2015; 15 (1): $13-20$

24. Brasil. Ministério da Saúde. Secretaria de Atenção à Saúde. Departamento de Atenção Básica. Saúde da criança: aleitamento materno e alimentação complementar / Ministério da Saúde, Secretaria de Atenção à Saúde, Departamento de Atenção Básica. Cadernos de Atenção Básica nº 23. 2 ed. Brasília, DF; 2015.

Received on February 23, 2018

Final version presented on November 21, 2018

Approved on July 15, 2019
25. Kao APOG, Guedes ZCF, Santos AMN. Características da sucção não-nutritiva em RN a termo e pré-termo tardio. Rev Soc Bras Fonoaudiol. 2011; 16 (3): 298-303.

26. Fujinaga CI, Zamberlan NE, Rodarte MDO, Scochi CGS. Confiabilidade do instrumento de avaliação da prontidão do prematuro para alimentação oral. Pró-Fono R Atual Cient. 2007; 19 (2): 143-50.

27. Neiva FCB, Cattoni DM, Ramos JLA, Issler H. Desmame precoce: implicações para o desenvolvimento motor-oral. J Pediatr (Rio J.). 2003; 79 (1): 7-12.

28. Cordeiro, MT. Postura, posição e pega adequadas: um bom início para amamentação. In: José Dias Rego. Aleitamento materno. 2 ed. São Paulo. Atheneu: 2009. p. 159-82.

29. Dennis CL, Jackson K, Watson J. Interventions for treating painful nipples among breastfeeding women. Cochrane Database of Systematic Reviews. 2014; 12: CD007366.

30. Xavier C. Assistência à Alimentação de Bebês Hospitalizados. In: Basseto MCA, Brock R, Wajnsztejn R. Neonatologia: Um Convite à Atuação Fonoaudiológica. São Paulo; Lovise, 1998. 